\title{
Numerical analysis of a deep excavation in front of MarmorKirken, Copenhagen
}

\author{
Fabio M. Soccodato* and Giuseppe Tropeano \\ Dept. of Civil, Environmental Engineering and Architecture (DICAAR), University of Cagliari \\ Via Marengo 2, 90123, Cagliari (Italy) \\ soccodato@unica.it
}

\begin{abstract}
In this paper, the main results of a numerical geotechnical analysis of the deep excavation carried out in front of MarmorKirken in Copenhagen are presented and compared with the observed performance. The excavation has a maximum depth of about $35 \mathrm{~m}$; a full top-down construction technique was adopted in order to minimize the effects induced by the excavation works on the monument. Foundation soils are characterized by the presence, starting from a depth of about $13 \mathrm{~m}$, of a limestone formation. The comparison between predicted and observed performance shows that a significant amount (about 50\%) of the maximum settlements experienced by the church occurred during the construction stage of the retaining wall panels in front of the church. Numerical analyses got the order of magnitude of displacements, but underpredicted both panel construction and excavation induced settlements of the church, while a better agreement was found for horizontal displacements.
\end{abstract}

Keywords: deep excavations, numerical analyses, soil-structure interaction

\section{Introduction}

The new Copenhagen underground line consists of two twin tunnels with internal diameter equal to $4.9 \mathrm{~m}$ and about $15.5 \mathrm{~km}$ in length. The metro path forms a ring which underpasses a large number of buildings constructed during different historical times, from the Middle Age up to present. The design also included 17 new stations: one of them is located very close to MarmorKirken, the most important monumental church in Denmark.

The evaluation of the effects induced by the station box excavation on the monument represented, as usual in this kind of projects, a key-step of the design. A joint effort of archeologists and of structural and geotechnical engineers is in fact needed in order to define reliable numerical models aimed to assess the expected damage (Burghignoli et al, 2013). The development of consistent geotechnical soil-structure interaction analyses is very important to obtain effective displacement fields to be applied to a refined structural model of building for the damage evaluation. In geotechnical analyses, a simplified but representative model of the building, in terms of loading and stiffness, needs in fact to be included (Rampello et al., 2012; Boldini et al., 2018). 
In the following, the main information about the excavation plan, the structure of the church, the foundation soils and the monitoring system are briefly illustrated. Successively, some of the results of a three dimensional (3D) geotechnical soil-structure interaction analysis are presented and compared to the observed performance.

\section{MarmorKirken station}

Fig. 1a shows a plan view of the area, with MarmorKirken and the station box boundaries highlighted. Plan and two representative sections of the station are also shown in Fig. $1 \mathrm{~b}$ and Fig. 1c, respectively. The excavation reaches a maximum depth of about $35 \mathrm{~m}$; the reinforced concrete diaphragm walls, constituted by $2.5 \times 1.5 \mathrm{~m}$ panels, have a length of $40 \mathrm{~m}$. The walls are located only $3 \mathrm{~m}$ away from the foundations of the church; along the other sides of the excavation, civil buildings are also quite close to the station box.

In order to minimize the effects induced by the excavation works on existing buildings, the design required a full top-down construction technique, with the erection of floor slabs at each level before each progressive deepening of the excavation.

Construction works of Frederik church, better known as MarmorKirken (MMK), started in 1749 and ended in 1894. Schematically, from a structural point of view, the church can be divided into four parts: foundation, lower part, upper part and dome, as shown in Fig. 2a. The ring foundation, with an outer and inner diameter of about 50 and $25 \mathrm{~m}$, respectively, is made up of large granite blocks, with a thickness of about 3 $\mathrm{m}$. It is placed on a wooden plank resting on a network of short wooden piles, aimed to the reinforcement of the shallow soil layers characterized by poor mechanical properties. The lower part of the church (entrance level), up to the arcades of the first level, consists mainly of blocks of marble; in the upper part (drum level), different materials were used (mainly masonry, but also rock blocks). The church is characterized by the largest masonry dome in all of Scandinavia, with a height of $46 \mathrm{~m}$ and a diameter of $31 \mathrm{~m}$.

As often happens when a project involves ancient buildings, the information about the geometries, the construction techniques and the physical and mechanical characteristics of the building materials are rather approximate, being constituted by drawings and documents collected and prepared by historians and archaeologists. Therefore, as part of the design, it was deemed necessary to carry out a series of surveys aimed to acquire further information. More in detail, a laser-scan technique was used in order to obtain a very detailed 3D model of the structure; a limited number of endoscopies for the identification of materials, boreholes for retrieving rock samples later tested in the laboratory, sonic and flat jack tests on masonry were executed. As for the foundations, excavation pits and boreholes were carried out to assess the geometry and to retrieve rock samples. Finally, a photographic survey of the existing crack pattern, which was found not particularly significant, was realized. All these data have been used for the definition and calibration of a refined structural numerical model of the church. 
a)

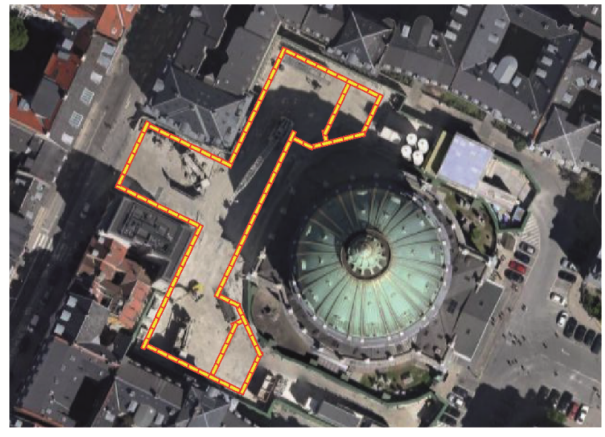

b)

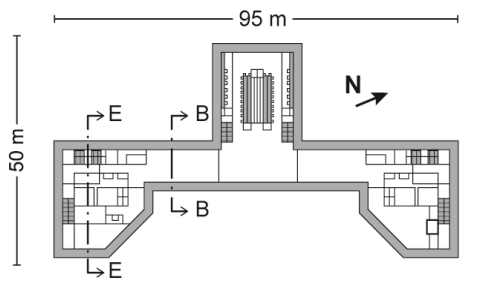

c)

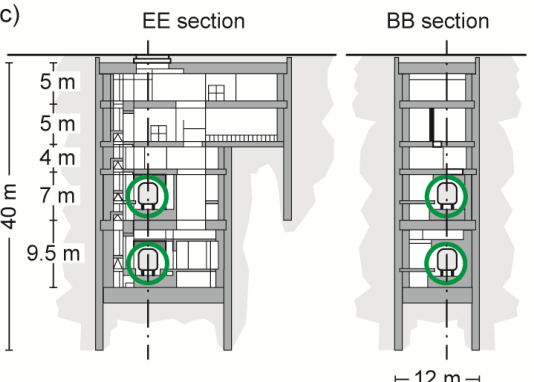

Fig. 1 View of MarmorKirken area (a), plan view (b) and sections of the station box (c)

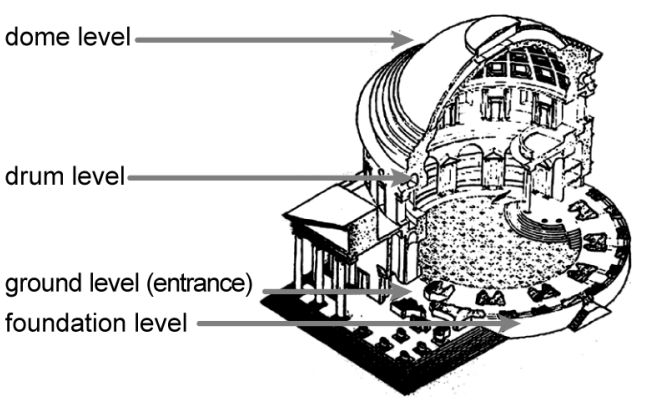

a)

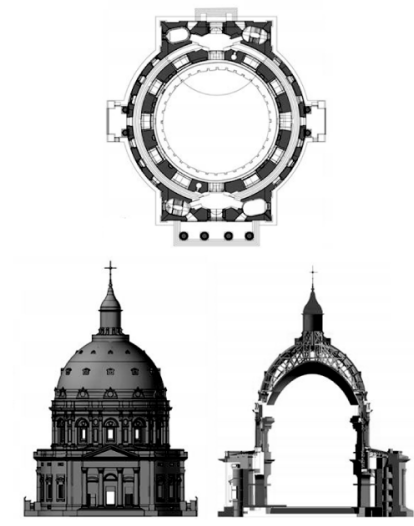

b)

Fig. 2 MarmorKirken: schematic view (a) and output of the laser-scan survey (b)

\section{Soil profile}

The stratigraphic profile and the physical and mechanical properties of the foundation soils in the area have been obtained from an extensive geotechnical investigation, which included in situ and laboratory tests carried out on samples retrieved from bore- 
holes. Fig. 3 shows the reference stratigraphic profile with the identification of the foundation level and of excavation/support depths. The surface layer (FY) is rather heterogeneous, being characterized by the presence of clay, sand, peat and, locally, building materials and remains of ancient constructions. A silty clay of medium plasticity (ML), overconsolidated, is in transition with the underlying medium to very dense coarse-grained unit DS/DG. The Copenhagen Limestone formation (UCL/MCL) is characterized by an upper layer (UCL HP) slightly more fractured than the rock formation at depth. The groundwater regime, in agreement with piezometer data, is substantially hydrostatic, with a piezometric level at the mean sea level, which is in fact only a few hundred meters away from the church.

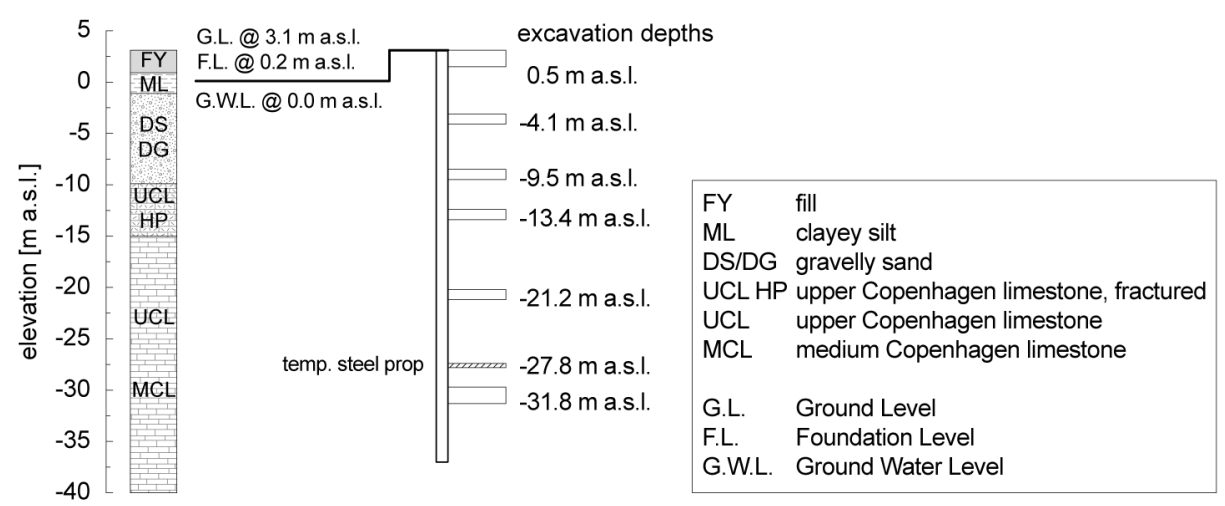

Fig. 3 Soil profile and layout of excavation

\section{Monitoring system}

The project included a detailed monitoring plan, with an automatic remote acquisition system in order to provide real-time information about the effects of construction activities. Fig. 4 shows the location of the geotechnical instrumentation and of the precision levelling points (LVPs) placed on structural sections of the church.

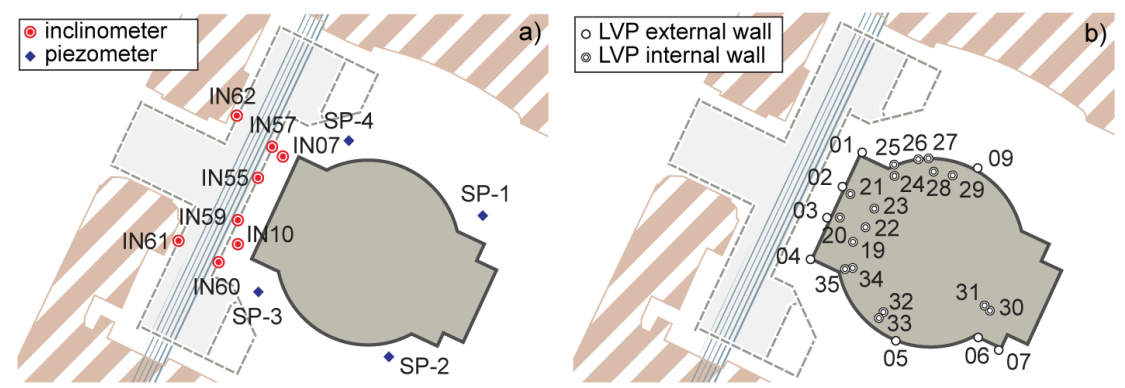

Fig. 4 Monitoring system: geotechnical instrumentation (a) and levelling points (b) 


\section{Numerical analysis}

The 3D numerical analysis was carried out with PLAXIS 3D code (Plaxis bv, 2013). The mesh $(140 \times 130 \times 53 \mathrm{~m})$ is shown in Fig. 5: about 130000 finite elements were used to model soils, retaining structures and buildings. The well-known Hardening Soil model (Schanz et al., 1999) was adopted for all the geological material: Tab. 1 lists the model parameters used in the class A prediction described in this paper. Existing buildings and MMK were modeled as a linear elastic equivalent solid corresponding to the geometry of building below ground level; building dead loads acting on the foundation were obtained from structural analyses. Model parameters used for the structures and buildings are reported in Tab. 2. The numerical analysis includes the following steps: initial geostatic condition, activation of buildings, constructions of the retaining wall panels and, finally, excavation stages following the design construction sequence. The construction of panels in front of MMK has been simulated, as a first approximation, adopting the usual numerical technique constituted by 3 stages: i) panel excavation with applied slurry hydrostatic pressures, ii) applying fresh concrete pressures and iii) panel activation with cured concrete properties (Lings et al., 1994). This technique was applied at the same time for all primary panels and, successively, again at the same time, to all secondary panels, as proposed by Conti et al. (2012).

(a)

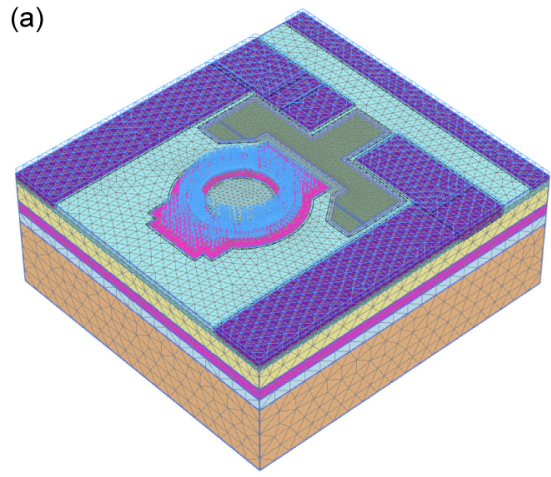

(b)

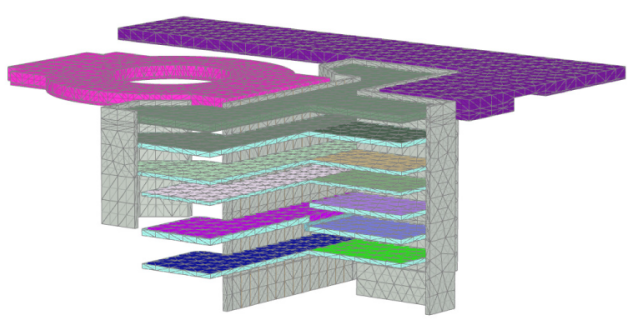

Fig. 5 3D numerical model: mesh (a) and structures (b)

Table 1 Hardening Soil model parameters adopted in the analyses $\left(p_{\text {ref }}=100 \mathrm{kPa}\right)$

\begin{tabular}{lccccccccccc}
\hline Unit & $\begin{array}{c}z_{\text {top }} \\
{[\mathrm{m} \text { a.s.l. }]}\end{array}$ & $\begin{array}{c}\gamma \\
{\left[\mathrm{kN} / \mathrm{m}^{3}\right]}\end{array}$ & $\begin{array}{c}K 0 \\
{[-]}\end{array}$ & $\begin{array}{c}\text { OCR } \\
{[-]}\end{array}$ & $\begin{array}{c}c^{\prime} \\
{[\mathrm{kPa}]}\end{array}$ & $\begin{array}{c}\varphi^{\prime} \\
{\left[{ }^{\circ}\right]}\end{array}$ & $\begin{array}{c}E_{\text {url, ref }} \\
{[\mathrm{MPa}]}\end{array}$ & $\begin{array}{c}v^{\prime} \text { ur } \\
{[-]}\end{array}$ & $\begin{array}{c}\text { E50,ref } \\
{[\mathrm{MPa}]}\end{array}$ & $\begin{array}{c}\text { Eoed,ref } \\
{[\mathrm{MPa}]}\end{array}$ & $m$ \\
\hline FY & 3.1 & 19 & 0.58 & 1.0 & 0.5 & 25 & 9 & 0.30 & 3 & 3 & 0.5 \\
ML & 0.9 & 20 & 0.91 & 12 & 15 & 32 & 81 & 0.30 & 27 & 27 & 0.5 \\
DS/DG & -1.1 & 21 & 0.93 & 10 & 0.5 & 38 & 525 & 0.25 & 175 & 175 & 0.5 \\
UCL HP & -15.0 & 21 & 0.68 & 10 & 100 & 45 & 720 & 0.30 & 250 & 250 & 0.5 \\
UCL/MCL & -20.0 & 21 & 0.68 & 10 & 100 & 45 & 1500 & 0.30 & 500 & 500 & 0.5 \\
\hline
\end{tabular}


Table 2 Properties of structures

\begin{tabular}{lcccc}
\hline Structure & $\begin{array}{c}\gamma \\
{\left[\mathrm{kN} / \mathrm{m}^{3}\right]}\end{array}$ & $\begin{array}{c}E \\
{[\mathrm{MPa}]}\end{array}$ & $\begin{array}{c}v \\
{[-]}\end{array}$ & $\begin{array}{c}\text { load } \\
{[\mathrm{kPa}]}\end{array}$ \\
\hline MMK foundation & 22.5 & 600 & 0.10 & 250 (average value) \\
Panels & 25 & 33 & 0.15 & - \\
Top slab & $21^{1}$ & $30^{1}$ & 0.15 & - \\
Slabs & $21^{1}$ & $9^{1}$ & 0.15 & - \\
Bottom slab & 25 & $9^{1}$ & 0.15 & - \\
Buildings foundation & 20 & 60 & 0.10 & 100 \\
\hline${ }^{1}$ Reduced value accounting for openings and sealing package at wall/slab connection
\end{tabular}

Observed and predicted horizontal displacements for some selected excavation stages are shown in Fig. 6. Data refer to inclinometers IN57 and IN07, the first one being installed inside the retaining wall and the second one located immediately (about $1 \mathrm{~m}$ ) at its back. Measures clearly indicate that, starting from about $10 \mathrm{~m}$ of depth, soil displacements are smaller than those exhibited by the wall. In other terms, a gap appears between soil and retaining wall due to the relatively high strength of the Copenhagen Limestone unit. Predicted wall displacements are somewhat smaller than those observed (IN57), even though a reasonable general agreement with the progression of the excavation is clearly apparent. When looking at soil horizontal displacements (IN07), the observed performance is in a good agreement with numerical results, except for shallow depths, where the analysis still underpredicts measurements.

Fig. 7 reports the time evolution of MMK settlements, as obtained from LVPs. The construction of panels in front of MMK caused a maximum settlement of about $3 \mathrm{~mm}$ (starting values at the beginning of the graph); the following excavation stages increased the maximum settlements up to about $7 \mathrm{~mm}$. It is worth noting that, in this case history, nearly one half of the total settlements induced on the building appeared before starting the box station excavation. Settlement profiles at MMK foundation level predicted by the numerical analysis are shown in Fig. 8. As compared to observed values, a large underprediction is once again apparent. More in detail, for panel construction stage, the ratio between maximum observed and predicted settlement is about 7.5 (3.0:0.4) while for excavation stages, in terms of incremental values, is about 4 (4.0:1.3), significantly less.

The real time acquisition of monitoring data during the first stages of excavation allowed updating, during construction activities, the damage assessment of the church. Considering the qualitative agreement between the shapes of the predicted and observed displacement fields, this was done by multiplying the settlement fields obtained from the class A prediction by a factor equal to 5 and by repeating the structural analyses with the updated estimated settlements.

Differences between numerical predictions and observed performances may in fact arise from several issues, and more probably from a combination of them. They include the adequateness of constitutive models, the appropriate selection of soil parameters and of stiffness (including its time evolution) of reinforced concrete structures (wall and slabs), the correct evaluation of building loads and stiffness and, finally, the 
assessment of quality of construction works (especially for panel construction stages). The effects of some of these issues in this case history are currently under investigation.

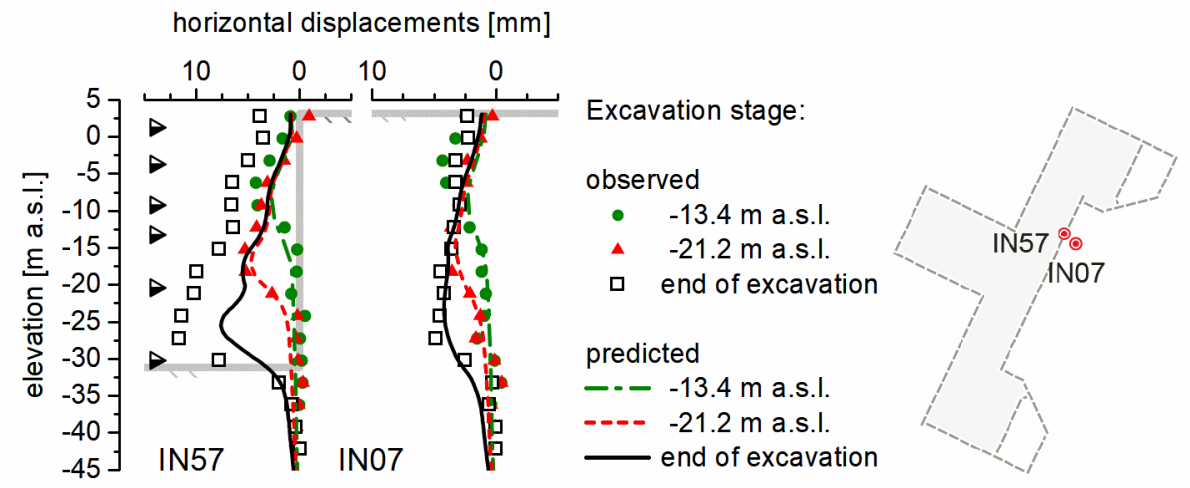

Fig. 6 Observed and predicted horizontal displacements

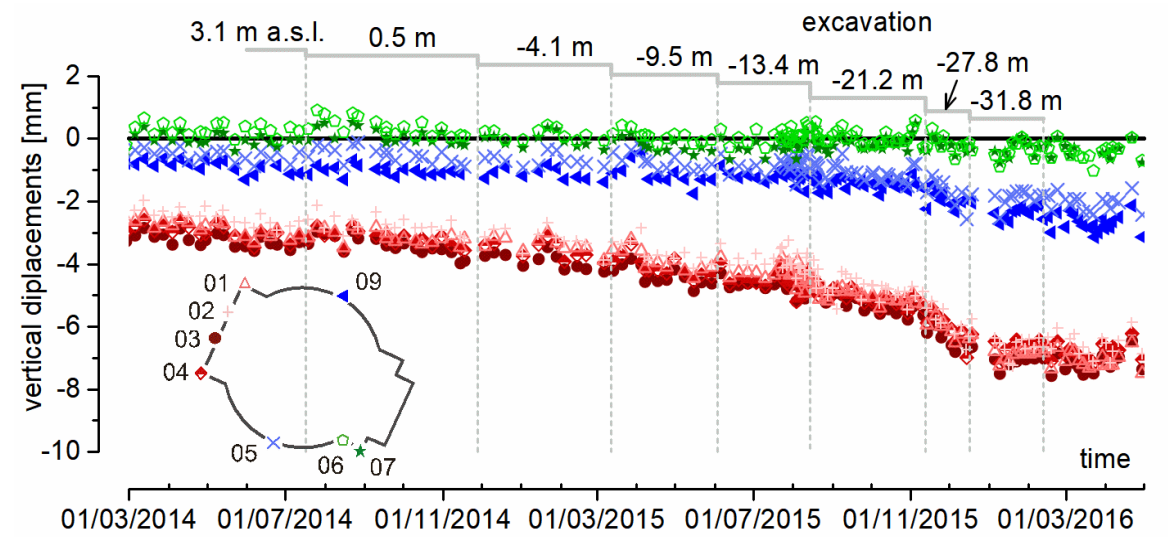

Fig. 7 Time evolution of MMK settlements (LVPs measurements)

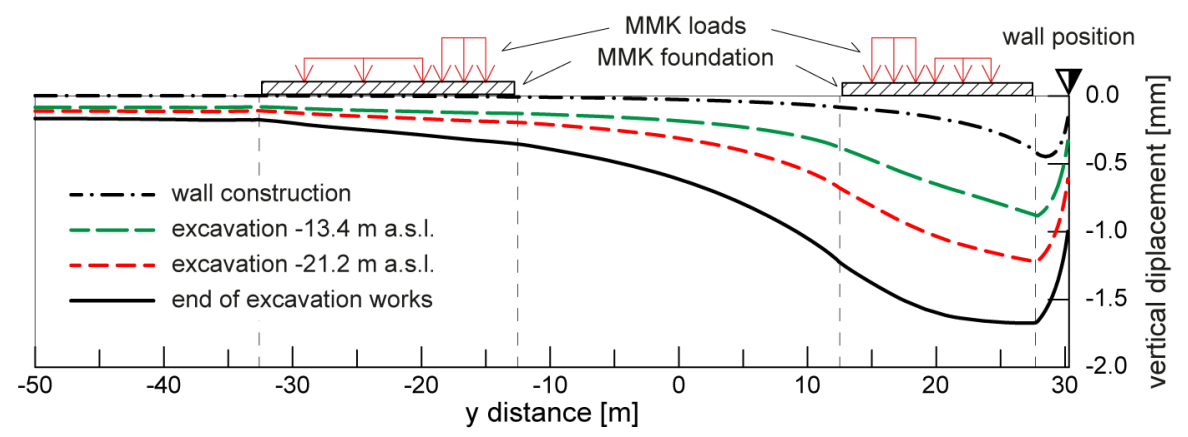

Fig. 8 Predicted settlements at MMK foundation level (along main longitudinal axis) 


\section{Conclusions}

In the present study, the main results of a 3D finite element analysis of the deep excavation carried out in front of MarmorKirken in Copenhagen have been presented and discussed. Observed performance shows that displacement fields were small, less than $10 \mathrm{~mm}$. A significant amount (about 50\%) of maximum settlements experienced by the church happened during the construction stage of the retaining wall panels in front of the church.

Numerical analyses got the order of magnitude of displacements, but underpredicted both panel construction and excavation induced settlements of the church; a better agreement between numerical results and measurements was found for horizontal displacements. It is believed that the discrepancy between numerical predictions and observed performance is due to a combined effect of the selection of soil models and parameters, of the evaluation of stiffness of retaining structures and of the quality of construction activities.

Acknowledgements The Authors thank Mr G. Fantauzzi for sharing information about this case history. The Authors are also grateful to Metroselskabet and SaliniImpregilo for the permission to publish monitoring data.

\section{References}

Boldini, D., Losacco, N., Bertolin, S., and Amorosi, A. (2018). Finite Element modelling of tunnelling-induced displacements on framed structures. Tunnelling and Underground Space Technology. 80, 222-231.

Burghignoli A., Callisto L., Rampello S., Soccodato F.M., and Viggiani, G.M.B. (2013) The crossing of the hystorical centre of Rome by the new underground Line C: a study of soilstructure interaction for hystorical buildings. In Geotechnics and Heritage: Case Histories, 97-136. CRC PRESS.

Conti, R., de Sanctis, L., and Viggiani, G.M.B. (2012). Numerical modelling of installation effects for diaphragm walls in sand. Acta Geotechnica 7, 219-237.

Lings, M.L., Ng, C.W.W., and Nash, D.F.T. (1994) The lateral pressure of wet concrete in diaphragm wall panels cast under bentonite. Proc Inst Civ Eng Geotech Eng, 107, 163-172.

Rampello, S., Callisto, L., Soccodato, F.M., and Viggiani, G.M.B. (2012). Evaluating the effects of tunnelling on historical buildings: The example of a new subway in Rome. Proc. $7^{\text {th }}$ Int. Symp. on Geotechnical Aspects of Underground Construction in Soft Ground, May 1618 2011, Rome, Italy, 65-80.

Plaxis B.V. (2013). Plaxis 3D User' Manual.

Schanz, P.A., Vermeer, P.A., and Bonnier, P.G. (1999). The hardening soil model: Formulation and verification. In Beyond 2000 in Computational Geotechnics, 281-296. Balkema, Rotterdam. 